\title{
INFLUENCE OF THE PRESENCE OF LONG CHAIN FATTY ACIDS (LCFAS) IN THE SEWAGE ON THE GROWTH OF M. PARVICELLA IN ACTIVATED SLUDGE WASTEWATER TREATMENT PLANTS
}

\author{
D. MAMAIS ${ }^{1^{*}}$ \\ G, NIKITOPOULOS ${ }^{1}$ \\ E. ANDRONIKOU ${ }^{1}$ \\ E. GAVALAKIS ${ }^{1}$ \\ A. ANDREADAKIS ${ }^{1}$ \\ C. NOUTSOPOULOS ${ }^{1}$ \\ C. GIOTAKIS ${ }^{2}$ \\ G. TSIMARAKIS ${ }^{2}$
}

${ }^{1}$ Sanitary Engineering Laboratory, Department of Water Resources Hydraulics and Maritime Works, Faculty of Civil Enging., National Technical University of Athens, 5 Iroon Polytechniou Str., Zografou Athens 15773, Greece

${ }^{2}$ Municipal Enterprise for Water and Sewage of Ioannina Ioannina, Greece
Selected from papers presented in $9^{\text {th }}$ International Conference on Environmental Science and Technology (9CEST2005)

1-3 September 2005, Rhodes island, Greece *to whom all correspondence should be addressed Tel.: +30 210 7722897; Fax: +30 2107722899 e-mail: mamais@central.ntua.gr

\begin{abstract}
Foaming and bulking problems in activated sludge treatment plants are associated to the presence of a variety of filamentous bacteria. However, it has been observed that $M$. parvicella is the most frequent filamentous microorganism causing sludge bulking and foaming, especially in treatment plants involving nutrients removal.
\end{abstract}

High sludge retention time, low DO, low temperature, presence of anoxic, anaerobic, and intermittently aerated zones, are the most commonly cited conditions associated with its growth. Substrate composition is another significant factor, as it has been found that slowly degradable organic material may favour the growth of $M$. parvicella. If has also been suggested that $M$. parvicella may preferably store long chain fatty acids (LCFAs) under anaerobic conditions and subsequently use it for growth.

The paper presents the results of an investigation conducted at the wastewater treatment plant of Ioannina, aiming to establish a cause-effect relationship between the presence of LCFAs and the abundance of $M$. parvicella. This investigation is a part of a wider study sponsored by the Greek Secretariat for Research, under the PENED programme.

The duration of the investigation covers 8 months, from January 2004 to August 2004. During this period samples were taken from the sewage collection network and wastewater treatment plant of Ioannina and analysed for, among other parameters, LCFAs and total fatty acids while samples of the mixed liquor and the foam in the biological reactors were microscopically analysed in order to determine the presence and amount of various types of filamentous bacteria.

Two main conclusions were drawn. The first is related to the effect of temperature on the growth of M. parvicella, indicating that the growth of this specific filamentous bacterium is favoured by low temperatures (generally below $20{ }^{\circ} \mathrm{C}$ ), while higher temperatures cause the practical elimination of $M$. parvicella, irrespectively of other factors. This conclusion verifies previous studies in pilot units and full scale plants. The second conclusion is that during winter periods there seems to be a positive correlation, between the presence of fatty acids and more specifically LCFAs and the amount of M. parvicella.

KEYWORDS: Activated sludge; filamentous bulking; long chain fatty acids; foaming 


\section{INTRODUCTION}

Foaming and bulking problems in activated sludge treatment plants are associated to the presence of a variety of filamentous bacteria. However, it has been observed that $M$. parvicella is the most frequent filamentous microorganism causing sludge bulking and foaming, especially in treatment plants involving nutrients removal [1, 2].

High sludge retention time, low DO, low temperature, presence of anoxic, anaerobic, and intermittently aerated zones, are the most commonly cited conditions associated with its growth [2]. Substrate composition is another significant factor, as it has been found that slowly degradable organic material may favour the growth of $M$. parvicella. If has also been suggested that $M$. parvicella may preferably store long chain fatty acids (LCFAs) under anaerobic conditions and subsequently use it for growth $[3,4]$.

Sewer systems may often operate as bioreactors causing considerable wastewater quality changes, influencing the composition of influent wastewater and particularly the relative magnitudes of readily biodegradable, easily hydrolysable and slowly hydrolysable fractions [5]. A change in the composition of influent wastewater that will result in the increase in the concentration of hydrolysed lipids especially in the form LCFAs may be responsible for the excessive growth of filamentous bacteria such as M. parvicella.

The paper presents a new method for the analysis of LCFAs in wastewater, which constitutes a "tool" for the investigation of the relationship between filamentous bacteria and the existence of LCFAs in urban wastewater. The LCFAs determination method that was developed can be utilized for the calculation of both free LCFAs (sample without saponification) and total LCFAs contained in the samples (after sample saponification). The method was applied to the wastewater treatment plant of Ioannina, aiming to establish a cause-effect relationship between the presence of LCFAs and the abundance of $M$. parvicella. This investigation is a part of a wider study sponsored by the Greek Secretariat for Research, under the PENED programme.

\section{MATERIALS AND METHODS}

The duration of the investigation covers 8 months, from January 2004 to August 2004. During this period samples were taken from the sewage collector and treatment plant of loannina and analysed for, among other parameters, LCFAs and total fatty acids while samples of the mixed liquor and the foam in the biological reactors were microscopically analysed in order to determine the presence and amount of various types of filamentous bacteria.

\section{loannina sewage treatment plant}

The sewage treatment plant (STP) of loannina serves a population equivalent of approximately 135,000 . Sewage is transported to the plant via a main collector with a diameter of $1.2 \mathrm{~m}$ and $4 \mathrm{~km}$ in length. In addition to the sewage, the plant receives septage which enters the plant after preliminary treatment. Subsequently the mixture receives primary treatment and following this biological treatment by the activated sludge process. The treated effluent after chlorination is mixed with surface waters and is mainly used for irrigation. The produced sludge is anaerobically digested, dewatered and disposed off by landfilling.

\section{Long chain fatty acids measurements}

Measurements were performed with a Perkin Elmer AutoSystem XL gas chromatographer fitted with a split/splitless injector for capillary columns and a Flame Ionization Detector. The column was a BP21-SGE fused silica capillary column $(50 \mathrm{~m} \times 0,22 \mathrm{~mm}$ i.d., $0,25 \mu \mathrm{m}$ film thickness) with Polyethylene glycol as a stationary phase combined with a pre-column of $5 \mathrm{~m}$ length and 0,22 $\mathrm{mm}$ i.d. Carrier gas was helium (purity 99,999 \%) and the whole chromatographic system was controlled by Turbochrom software of PE Nelson.

Samples were collected in glass bottles previously cleaned with $\mathrm{HCl}$ and stored at $4{ }^{\circ} \mathrm{C}$ until analysis. Analyses were performed with the least possible delay. All standards of LCFAs were analytical grade $>99 \%$ and purchased from Labor Dr. Ehrenstorfer. In more detail, four different fatty acids were studied, three of them with even number of carbon atoms (palmitic, stearic and oleic acid) and one with odd number of carbon atoms (margaric acid). For the saponification of samples sodium hydroxide from Merck kGaA was used and hydrochloric 
acid from Riedel-de Haën ( $\min 37 \%$ ) was added to bring the sufficient $\mathrm{pH}$ to the samples. Finally, chloroform from Riedel-de Haën (assay min 99,8 \%) was used as extraction solvent.

Extraction method: $100 \mathrm{~mL}$ of wastewater were transferred to a volumetric flask which was placed in a sonicated bath for $6 \mathrm{~h}$. Then, $\mathrm{HCl}(1: 1)$ was added to bring the $\mathrm{pH}$ to 1 . The sample was transferred to a separatory funnel and $20 \mathrm{~mL}$ chloroform were added. The mixture was shaken for 2 minutes and the organic phase was collected after decantation. The extraction was repeated two times. The extracts were mixed, filtered with glass fibre filter 47 $\mathrm{mm}$ and concentrated to dryness using nitrogen gas at $40^{\circ} \mathrm{C}$. The residue was dissolved in a suitable volume of chloroform and homogenized.

Saponification: Hydrolysis of glycerides by sodium hydroxide (saponification) before the use of the extraction method was required for the calculation of total LCFAs that exist in sewages samples. $100 \mathrm{~mL}$ of sample were mixed with $20 \mathrm{~mL}$ deionised water, $20 \mathrm{~mL}$ ethanol $96 \%$ and $5 \mathrm{~g} \mathrm{NaOH}$ in a distilling flask. Using vertical refluxing device, the mix was boiled for 30 minutes in a hot water bath. The flask was then removed from water bath, cooled at room temperature and $\mathrm{HCl}(1: 1)$ was added to bring the $\mathrm{pH}$ to 7 .

Calibration: Each of standards of LCFAs was dissolved in chloroform in order to construct calibration curves for each fatty acid (1-10 ppm and 10-100 ppm).

GC analysis: A $1 \mu \mathrm{L}$ aliquot of the extract was injected in the gas chromatograph, using split mode 50:1. The GC parameters were: Pressure of carrier gas: 60 psi, Injector temperature: $280{ }^{\circ} \mathrm{C}$, Oven temperature program: $180{ }^{\circ} \mathrm{C}(1 \mathrm{~min}), 8^{\circ} \mathrm{C} / \mathrm{min}$, up to $220{ }^{\circ} \mathrm{C}$, Detector temperature: $280^{\circ} \mathrm{C}$.

The concentration of long chain fatty acids in the samples was calculated using the constructed calibration curves for each fatty acid.

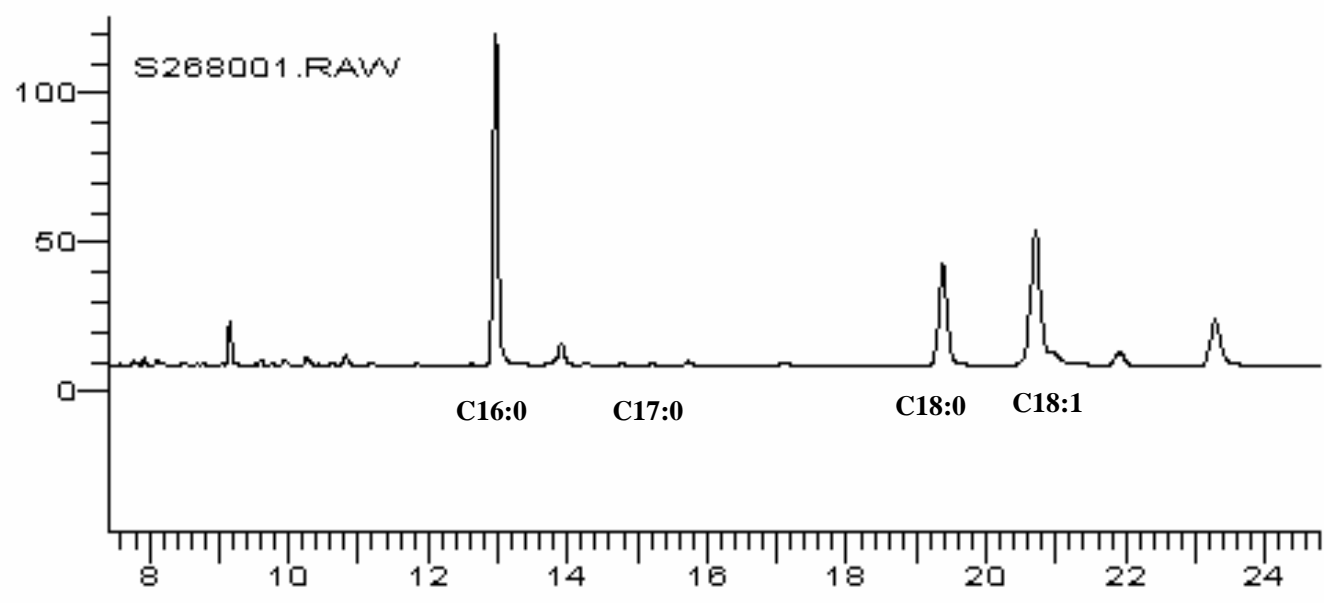

Figure 1. Typical chromatogram of wastewater LCFAs analysis from the influent in the wastewater treatment plant of loannina

\section{Identification and enumeration}

Microscopic examination of the sludges was performed according to [6] and [7]. M.parvicella levels in the activated sludge samples were estimated in terms of intersections of gram positive non-branched filaments $>3 \mu \mathrm{m}$ in length and $<1.5 \mu \mathrm{m}$ wide, per gram of mixed liquor suspended solids [3].

\section{RESULTS}

Total LCFAs concentration in the untreated wastewater from the city of loannina ranged from 8 to $50 \mathrm{mg} \mathrm{I}^{-1}$ The main LCFAs detected were palmitic acid, followed by stearic and oleic acids (Figure 2). All three long chain fatty acids have been reported to promote the growth of $M$ parvicella in activated sludge systems [3, 4, 8, 9,10, 11]. 
According to the results of analyses conducted following saponification of samples, free LCFAs concentration ranged from $41 \%$ to $94 \%$ of the total LCFAs with an average of $76 \%$. Both free and total LCFAs were reduced during transportation through the $4 \mathrm{Km}$ long main sewerage collector, by $45 \%$ and $48 \%$ respectively. Average total LCFAs at the start of the main collector and at the influent to the treatment plant was $26 \mathrm{mg} \mathrm{I}^{-1}$ and $13,7 \mathrm{mg} \mathrm{l}^{-1}$., respectively. This decrease through the sewer system can be attributed to both settlement and consumption of LCFAs by the biofilm and the suspended biomass in the sewer network [12]. According to the results it appears that the uptake rate of LCFAs is somewhat higher than the rate of lipids and fats hydrolysis. However it was not possible to establish a correlation between the ratio of free to total LCFAs and the residence time in the sewer.

Average free and total LCFAs concentrations measured in raw wastewater of loannina, in the preliminary treated and the primary effluent wastewater are shown in Table 1. According to these measurements it appears that there is a significant increase in both free and total LCFAs concentrations in preliminary treated wastewater compared to the raw wastewater. This increase is attributed to the septage and the recycle stream from the sludge treatment facilities that are discharged ahead of the grit removal facilities. Therefore both septage and sludge recycle streams may contribute significantly to the amount of LCFAs available to filamentous bacteria in the activated sludge system.

Table 1. Average free and total LCFAs concentrations in the Sewage Treatment Plant of Ioannina

\begin{tabular}{|c|c|c|}
\hline Sample site & $\begin{array}{c}\text { Free LCFAs, } \\
\left(\mathrm{mg} \mathrm{l}^{-1}\right)\end{array}$ & $\begin{array}{c}\text { Total LCFAs, } \\
\left(\mathrm{mg} \mathrm{l}^{-1}\right)\end{array}$ \\
\hline Raw wastewater & 10,4 & 13,7 \\
\hline Preliminary treated wastewater & 23,6 & 36,5 \\
\hline Primary treated wastewater & 13.7 & 16 \\
\hline
\end{tabular}

As shown in Table 1, a significant removal of both free and total LCFAs is achieved during primary sedimentation due to the combined effects of settlement, hydrolysis and uptake of LCFAs. Average reduction of free and total LCFAs is $42 \%$ and $54 \%$, respectively.

For the assessment of the settling characteristics of the activated sludge routine measurements of the Sludge Volume Index (SVI) were conducted. Furthermore microscopic analysis of the mixed liquor and foam samples was carried out throughout the monitoring period to determine the dominant filamentous microorganisms. According to the results of the microscopic analysis excessive growth of low F/M filamentous organisms was evidenced especially during winter months (Jan - Apr) with Filament Index ( $\mathrm{Fl}$ ) values ranging from 3 to 4 with an average value of 3,7. Throughout the winter period the relatively high FI values were followed by bulking phenomena. SVI values varied between $145-380 \mathrm{ml} / \mathrm{gSS}$ with an average value of $277 \mathrm{ml} / \mathrm{gSS}$. During winter months the dominant filamentous organisms in activated sludge samples in decreasing order of magnitude were M. parvicella, Type 0092, Type 0041 and Type 0675 (Figure 3) with average Specific FI (SFI) values of 3,8, 3,3, 1 and 0,9 respectively. The same filamentous microorganisms were also found in the foam samples (Figure 4) in the same order, with M.parvicella exhibiting an even higher SFI value (average $\mathrm{SFI}=4,4)$ due to the hydrophobic nature of its cell membrane.

The composition of filamentous bacteria in sludge biocenosis observed during summer months (May - Aug) was significantly different (Figures 3 and 4). The dominant filamentous microorganisms in decreasing order were Type 0092, Type 0675 and Type 0041. During summer the activated sludge exhibited better settling characteristics with SVI values in the range fro 115 to $147 \mathrm{ml} / \mathrm{gSS}$. The higher temperatures observed during summer months resulted in a significant decrease in M.parvicella. As shown in Figure 2 M.parvicella counts progressively decreased during summer months from values of $27 \times 10^{6}$ intersections/gVSS, at temperatures lower than $18^{\circ} \mathrm{C}$, to less than $1 \times 10^{6}$ at temperatures above $20^{\circ} \mathrm{C}$. It is interesting to note that during summer, as M.parvicella presence progressively decreased to almost complete disappearance another low F/M bacterium, Type 0092 became dominant in the sludge biocenosis. 


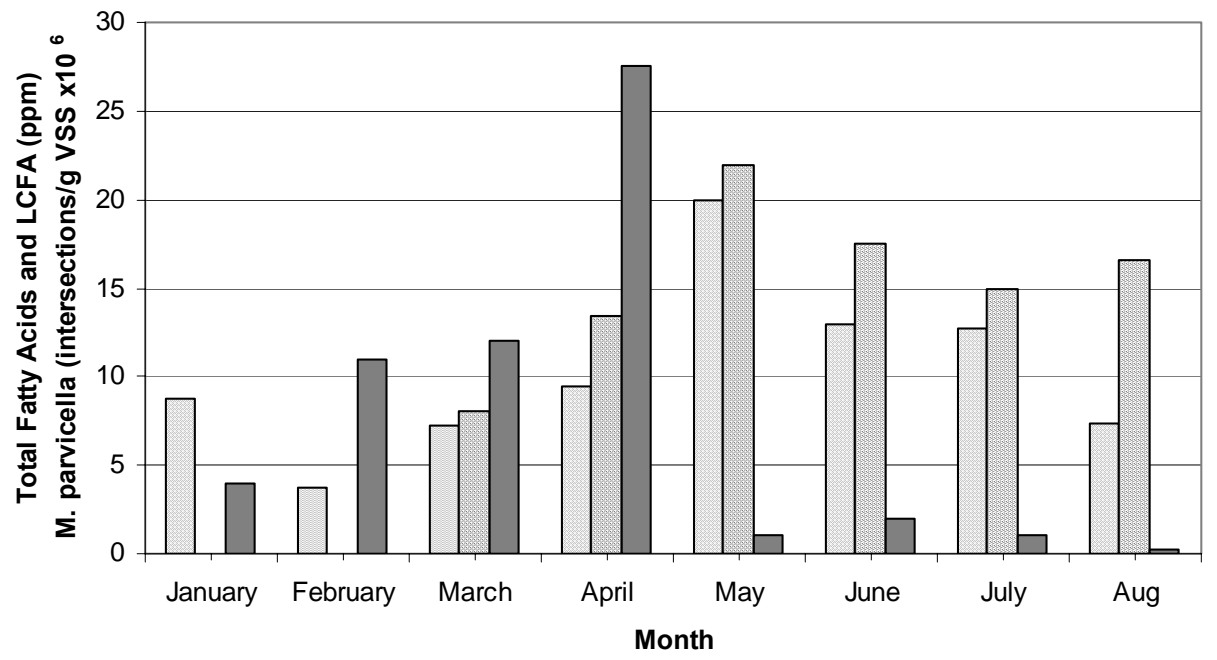

$\square$ Free LCFAs $\square$ Total LCFAs $\square$ M. parvicella

Figure 2. Correlation between M. parvicella abundance and free and total LCFAs concentrations

As shown in Figure 2 during winter period, appears to be a positive correlation between the presence of LCFAs and $M$. parvicella. However, the positive effect of LCFAs on the growth of $M$. parvicella is not as significant as the effect of temperature, since as shown in Figure 2, despite the fact that higher LCFAs were measured during the summer period, the elevated temperatures had a much more profound negative effect on the growth of $M$. parvicella. The verification and explanation of the seasonal variation of $M$. parvicella requires further investigation.

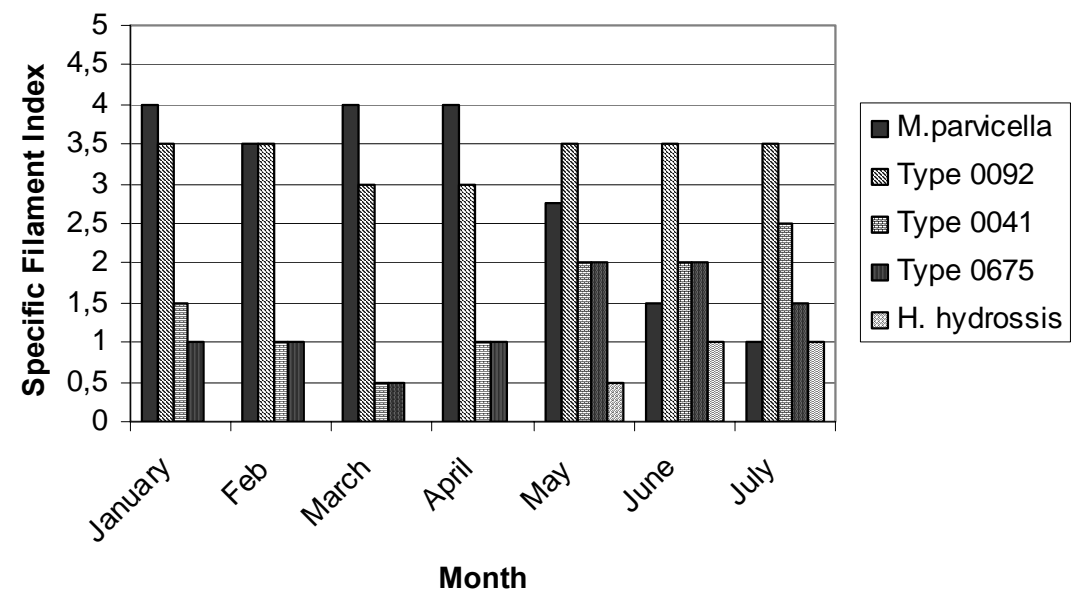

Figure 3. Dominant filamentous bacteria in activated sludge samples 


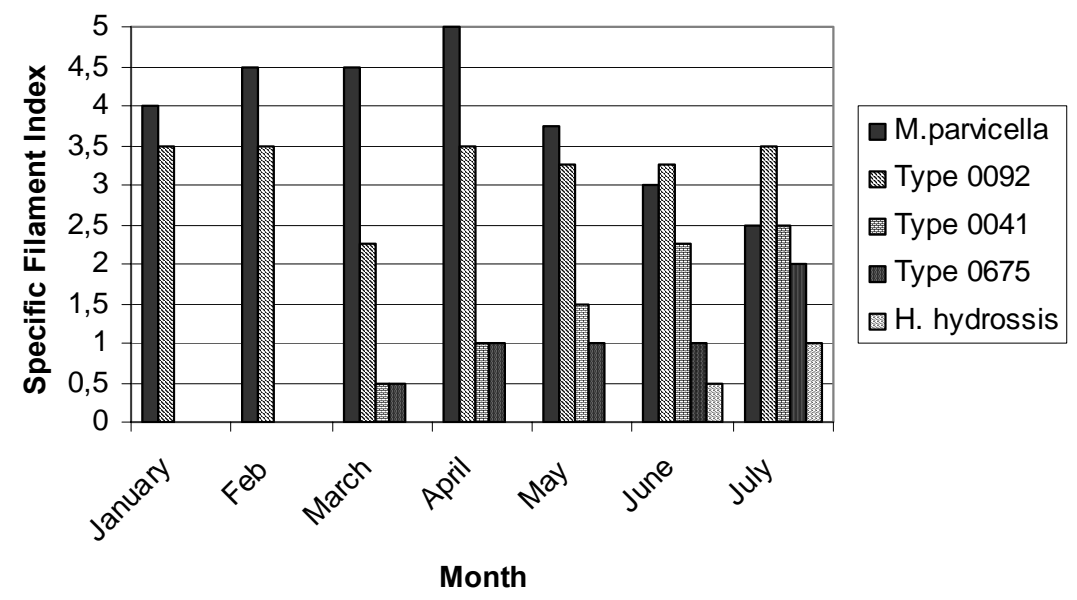

Figure 4. Dominant filamentous bacteria in the scum layer

\section{CONCLUSIONS}

The main conclusions can be summarised as follows:

- The main LCFAs detected in wastewater samples were palmitic acid, followed by stearic and oleic acids. All three acids have been reported to promote the growth of $M$ parvicella in activated sludge systems. Free LCFAs represent on average $76 \%$ of the total LCFAs, the percentage ranging from $41 \%$ to $94 \%$.

- Both free and total LCFAs were reduced during transportation through the $4 \mathrm{Km}$ long, sewer system by $45 \%$ and $48 \%$ respectively. However it was not possible to establish a correlation between the removal of LCFAs during transportation and the residence time in the sewer.

- Septage and sludge recycle streams appear to contain high amounts of LCFAs and contribute significantly to the amount of LCFAs available to filamentous bacteria in the activated sludge system.

- Primary sedimentation results in reduction of both free and total LCFAs by $42 \%$ and $54 \%$ respectively, due to the combined effects of settlement, hydrolysis and uptake.

With respect to the growth of filamentous bacteria and more specifically the growth of M. parvicella and the effect of LCFAs on the growth rate, two main conclusions were drawn.

- The first is related to the effect of temperature on the growth of $M$. parvicella, indicating that the growth of this specific filamentous bacterium is favoured by low temperatures (generally below $20^{\circ} \mathrm{C}$ ), while higher temperatures cause the practical elimination of $M$. parvicella, irrespectively of other factors. This conclusion verifies previous studies in pilot units [2 and 4].

- The second important conclusion is that during winter periods there seems to be a positive correlation, between the presence of fatty acids and more specifically LCFAs and the amount of M. parvicella. However, the effect of LCFAs on the growth of M. parvicella is not as significant as the effect of temperature, since despite the fact that higher LCFAs were measured during the summer period the growth of $M$. parvicella is inhibited at the elevated summer temperatures.

\section{ACKNOWLEDGMENTS}

Thanks are due to the director of the Municipal Enterprise for Water and Sewage of Ioannina and the personnel of the wastewater treatment plant of Ioannina for their cooperation and involvement in the project.

The paper presents the results of a wider work conducted in the framework of Action $8.3 \mathrm{pf}$ the Competitiveness Programme-PENED (2000-2006) sponsored by the European Union $75 \%$ and the Greek Secretariat for Research $25 \%$. 


\section{REFERENCES}

1. Andreadakis A.D. (1996), Filamentous bulking in nutrient removal plants, Proceedings of International Conference Protection and restoration of the environment III , pp 182-188, Technical University of Krete, August 1996, Chania, Crete.

2. Eikelboom D.H., Andreadakis A.D. and Andreasen K. (1998), Survey of the Filamentous Population in Nutrient Removal Plants in Four European Countries, Wat.Sci.Tech., 37(4-5), 281-289.

3. Mamais D., Andreadakis A.D.,.,Noutsopoulos C. and Kalergis C. (1998), Causes and Control Strategies of Microthrix parvicella Bulking and Foaming in Nutrient Removal Activated Sludge Systems, Wat.Sci.Tech., 37 (4/5), 9-17.

4. Noutsopoulos C., Mamais D. and Andreadakis A. (2002), The effect of the reactor configuration and the operational mode on M. parvicella bulking and foaming in nutrient removal activated sludge systems, Wat.Sci.Tech., 46 (1/2), 61-64.

5. Tanaka N. and Hvitved-Jacobsen T. (1998), Transformations of wastewater organic matter in sewers under changing aerobic/anaerobic conditions, Wat.Sci.Tech., 37 (1), 105-113.

6. Eikelboom D.H. and van Buijsen H.J.J. (1981), Microscopic sludge investigation manual, Delft:IMG-TNO, Report A94a.

7. Jenkins D., Richard M.G. and Daigger G.T. (1993), Manual on the causes and control of activated sludge bulking and foaming, 2nd Edition, Lewis Publishers, USA.

8. Slijkhuis H. (1983), Microthrix parvicella, a filamentous bacterium isolated from activated sludge: Cultivation in a chemically defined medium, Appl. Environ. Microbiol., 46 (4), 832-839.

9. Slijkhuis H., van-Groenestijn J.W. and Kylstra D.J. (1984), Microthrix parvicella, a filamentous bacterium isolated from activated sludge: Growth on tween 80 as carbon and energy source, Journal of General Microbiology, 130, 2035-2042.

10.Andreasen K. and Nielsen P.H. (1998), In situ characterization of substrate uptake by Microthrix parvicella using microautoradiography, Wat. Sci. Tech., 37 (4/5), 19-27.

11.Andreasen K. and Nielsen P.H. (2000), Growth of Microthrix Parvicella in nutrient removal activated sludge plants: studies of in situ physiology, Wat. Res., 34 (5), 1559-1569.

12. Nikitopoulos G. (2004), Development and application of a method for the determination of fatty acids with use of chromatography. Examination of their biodegradability in sewers, Postgraduate Thesis on Water Resources and Technology, National Technical University of Athens. 